\title{
Stress state along the western Nankai Trough subduction zone inferred from $b$-values, long-term slow-slip events, and low-frequency earthquakes
}

\author{
Keita Chiba* ${ }^{*}$
}

\begin{abstract}
The $b$-value of the Gutenberg-Richter law represents the ratio of earthquake magnitude to frequency of occurrence and is inversely proportional to differential stress. Repeating long-term slow-slip events (SSEs) and low-frequency earthquakes (LFEs) occur at subducting plate interfaces and have stress-dependent characteristics near the interface. In this study, a comprehensive regional $b$-value distribution is produced for the western Nankai Trough region, which highlights the relationship between $b$-values, SSEs, and LFEs. $b$-values vary along the strike direction of the subducting plate and are significantly lower $(b \sim 0.6)$ in central Shikoku district than elsewhere, where LFEs frequently occur. However, $b$-values in the source regions of other LFEs are moderate to high. These findings imply that $b$-values in the focal region are controlled by more than the LFE source process; indeed, if this source process were solely responsible, then high $b$-values would be expected. Meanwhile, the $V_{p} / V_{S}$ and $Q_{p}$ around the plate interface in central Shikoku estimated from seismic velocity and attenuation structure are smaller and larger than those in other regions with LFEs, respectively. SSEs with the migration toward central Shikoku also occurred during the analysis period, suggesting significant accumulation of shear stresses in the focal region, which reduced the $b$-values. These findings suggest that the spatial distributions of $b$-values are influenced by complicated stress and shear strength perturbations caused by SSEs and LFEs. On the other hand, the $b$-values in the region that underwent the greatest slip during the 1946 Nankai earthquake are not necessarily low, although the area covered by the $b$-value distribution is small owing to the lack of events on the updip side. Whereas the asperity areas of huge earthquakes are characterized by low $b$-values, the $b$-value distribution in the Nankai megathrust area is more complicated. It is considered that slow earthquakes, including SSEs and LFEs, are related to megathrust earthquakes via stress transfer from slow earthquakes to adjacent megathrust source regions. A unified analysis of $b$-values in the source regions of slow and megathrust earthquakes may be required to make precise estimates of the seismic hazard produced by a megathrust event.
\end{abstract}

Keywords: $b$-value, Stress state, Long-term slow-slip event, Low-frequency earthquake, Nankai Trough, Shikoku district

\section{Introduction}

A variety of slow earthquakes have been recorded in the western Nankai subduction zone in Japan during many years of land-based and offshore geophysical monitoring

*Correspondence: kchiba@sevo.kyushu-u.ac.jp

Institute of Seismology and Volcanology, Faculty of Science, Kyushu

University, 744 Motooka, Nishi-Ku, Fukuoka 819-0395, Japan (e.g., Obara et al. 2005; Kaneda et al. 2015). Slow earthquakes have characteristics of intermediate type of fault slip between the fast rupture of regular earthquakes and stable sliding along the plate interface and are sensitive to external stress perturbations in the focal area (e.g., Rubinstein et al. 2008; Chao et al. 2013; Obara and Kato 2016). Stress transfer from slow earthquakes to adjacent 
megathrust source faults increases the probability of triggering huge earthquakes (e.g., Obara and Kato 2016). Long-term slow-slip events (SSEs) are characterized by durations of months to years at depths of $20-40 \mathrm{~km}$. In the western Nankai Trough, between October 2000 and December 2012 (the time window analyzed in this study as described below), SSEs have been repeatedly observed in three subregions: (1) the Bungo Channel in 2003 and 2010, each releasing seismic moment equivalent to a $M_{w}$ 7.0-7.1 event (e.g., Ozawa et al. 2013; Ozawa 2017); (2) the Hyuga-nada Sea in 2005, 2007, and 2009, each releasing seismic moment equivalent to a $M_{w} \sim 6.7$ event (Yarai and Ozawa 2013); and (3) the western to central parts of Shikoku district, in 2004-2006 and 2011-2013, each with seismic moment release equivalent to a $M_{w} 6.0-6.3$ event (Kobayashi 2010; Takagi et al. 2016). In addition, other SSEs have also occurred in northern Miyazaki district and the Kii Channel, although none was observed in these regions during the time window of the present work (e.g., Ozawa et al. 2001; Kobayashi 2014; Geospatial Information Authority of Japan (GSI) 2016; Ozawa 2017). In addition, low-frequency earthquakes (LFEs) occur at the plate interface in the Nankai Trough region (e.g., Shelly et al. 2006; Ide et al. 2007). These slow earthquakes are often used as a reference to gauge the relative stress near the plate interface (e.g., Obara and Kato 2016).

The Gutenberg-Richter law is the power-law relationship between earthquake magnitude and frequency of occurrence:

$$
\log N=a-b M,
$$

where $N$ is the cumulative number of earthquakes with magnitude $\geq M$, and $a$ and $b$ are constants (Ishimoto and Iida 1939; Gutenberg and Richter 1944). The constant $b$ is a ratio that represents the relative frequency of occurrence of large earthquakes to that of small earthquakes and is commonly termed the " $b$-value." $b$-values vary somewhat with tectonic setting, but the worldwide average is $b \sim 1.0$ (e.g., Frohlich and Davis 1993). Physically, $b$-values depend on the stress and shear strength states, material heterogeneities, and temperature gradients (e.g., Mogi 1962; Scholz 1968, 2015; Warren and Latham 1970; Wyss 1973; Urbancic et al. 1992). Among these factors, many studies have suggested that $b$-values are inversely proportional to differential stress and/or shear strength (e.g., Scholz 1968, 2015; Wyss 1973; Urbancic et al. 1992). The stress dependence of $b$-values is very high in subduction zones (Wiemer and Benoit 1996), with many researchers having analyzed $b$-values related to plate locking and transient phenomena in different subduction zones (e.g., Ghosh et al. 2008; Nanjo and Yoshida 2018; Chiba 2019). In particular, Chiba (2019) investigated the stress dependence of $b$-values of earthquakes, long-term
SSEs, and LFEs along the plate interface in the Nankai Trough of southwestern Japan, focusing on a narrow area encompassing the Bungo Channel and Hyuga-nada regions, and found that $b$-values were moderate to low $(b=0.6-1.1)$ in regions with many SSEs. A comparison of the relationship between $b$-values and offshore interplate slip deficit rates along the Nankai Trough (e.g., Yokota et al. 2016) suggests that the cause of these low $b$-values is partial release of accumulated stress in regions where differential stress is high. In addition, Chiba (2019) suggested that LFEs play an important role in controlling the spatiotemporal distribution of $b$-values; for example, $b$-values in the Bungo Channel region, which shows frequent and vigorous LFE activity, are higher than those in the Hyuga-nada region, where no LFEs were detected. Using surveys of seismic velocity, attenuation, and anisotropy, Nakajima and Hasegawa (2016) found an inverse correlation between LFE activity and degree of metamorphism above the plate interface and inferred that undrained conditions in the overlying plate play an important role in LFE generation. In the case of an impermeable overlying plate, undrained conditions result in a low degree of metamorphism in the overlying plate and increased pore pressure along the plate interface, facilitating LFE generation. When the overlying plate is permeable, well-drained conditions result in a high degree of metamorphism in the overlying plate, and fluids that rise into it reduce the pore pressure along the plate interface, inhibiting LFE generation. It is thus expected that $b$-values in the source regions of LFEs are higher than those in regions lacking LFE activity. Chiba (2019) pointed out that the heterogeneous $b$-value distribution in the Bungo Channel and Hyuga-nada regions can be explained by the LFE generation model of Nakajima and Hasegawa (2016).

It is known that SSEs and LFEs occur in wide areas of the Nankai Trough (e.g., Obara and Kato 2016; Ozawa 2017). It is therefore important to develop a more comprehensive regional map of stress-dependent characteristics of $b$-values, LFEs, and SSEs. In this study, the Japan Unified high-resolution relocated Catalog for Earthquake (JUICE) (Yano et al. 2017) was used to examine $b$-values in the western Nankai Trough, including the Kii Peninsula and Hyuga-nada regions, to resolve the stress-dependent properties of SSEs and LFEs. Furthermore, the relationship between $b$-values and Nankai megathrust earthquakes is also discussed, based on both the stress-dependent characteristics of LFEs and SSEs and the relationship between slow earthquake generation and megathrust earthquakes.

\section{Data and methods}

The JUICE catalog is a high-resolution hypocenter cata$\log$ generated by applying the hypoDD relocation algorithm to differential travel-time data constructed from 
both waveform cross-correlations and picked phasearrival times of Hi-net catalog data (Waldhauser and Ellsworth 2000; Yano et al. 2017). The Hi-net permanent seismic network includes 1400 stations operated by $\mathrm{Hi}$ net and other organizations in Japan (Okada et al. 2004). The JUICE catalog includes more than 1 million events that occurred at depths shallower than $40 \mathrm{~km}$ between October 2000 and December 2012 (Yano et al. 2017). These data were used to obtain the $b$-values for the present study (Fig. 1a). Event magnitudes in the Hi-net catalog are determined from the maximum amplitudes of the velocity waveforms (Watanabe 1971). The uncertainties associated with catalog event locations are typically $<0.5 \mathrm{~km}$ in the horizontal direction and $<1.0 \mathrm{~km}$ in the vertical direction for areas with sufficient station coverage (Yano et al. 2017). Chiba (2019) showed that the magnitude histograms of JUICE data are very similar to those of the unified earthquake catalogs assembled by the Japanese Meteorological Agency (JMA catalog) in the area encompassing the Bungo Channel and Hyuga-nada regions, and the hypocenter distribution of the former catalog is narrower and finer than those of the latter. In addition, the $b$-value variations estimated from the JUICE catalog are clearer and sharper than those estimated from the JMA catalog. Improvements in the determination of the hypocenter locations via the hypoDD method may lead to a more precise $b$-value estimation. The JUICE catalog is thus more suitable for precise $b$-value analysis. Compared with the study in the narrow area encompassing the Bungo Channel and Hyuga-nada regions by Chiba (2019), the comprehensive $b$-value distribution in a larger geographic area is investigated in the present study. This study uses 32,784 events in an area bounded by $31.0^{\circ}-$ $34.2^{\circ} \mathrm{N}$ and $131.0^{\circ}-136.0^{\circ} \mathrm{E}$, with hypocenters deeper than $25 \mathrm{~km}$, to examine events in the Philippine Sea Plate and at the interface between the Amur and Philippine Sea plates in the focal region. Seismicity in the Philippine Sea Plate in the coupling zone is considered to reflect plate locking between the subducting and overriding plates (Matsumura 1997). Using these events in the analysis of $b$-values could therefore provide detailed insights into the stress state at the partially locked plate interface. The shallowest depth of selected events in this paper is slightly greater than that of Chiba (2019), in which the shallowest hypocentral depth was $20 \mathrm{~km}$, because many events in the Amur plate in Shikoku district are located at
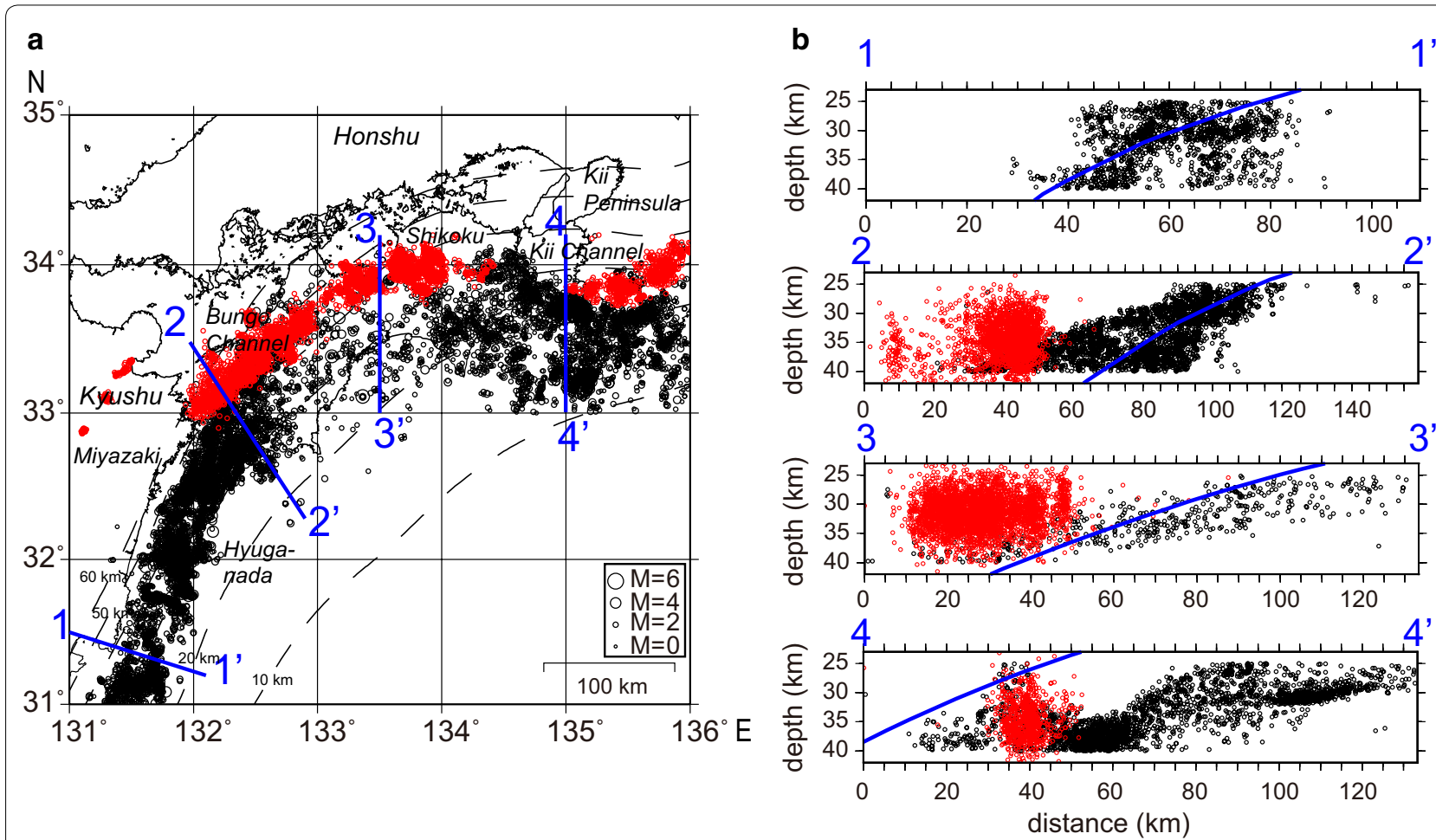

Fig. 1 a Epicenter distributions of $M \geq 1.4$ earthquakes at depths of 25-40 km obtained from the JUICE catalog (black circles) and of low-frequency earthquakes (LFEs) at depths of 20-50 km obtained from the JMA unified catalog (red circles). Non-LFE earthquakes are scaled by magnitude. Dotted black lines correspond to isodepth contours of the plate interface with labels in kilometers (Hayes et al. 2018). Four blue lines represent the locations of the cross sections in $\mathbf{b}$. $\mathbf{b}$ Hypocenter distributions projected onto four vertical transects in $\mathbf{a}$. All events that occurred within $50 \mathrm{~km}$ of each transect are plotted. Blue lines represent the upper surface of the subducting plate by Hayes et al. (2018) 
depths of $20-25 \mathrm{~km}$. Many extracted events are located in the Philippine Sea Plate and at the plate interface, even when only events deeper than $25 \mathrm{~km}$ are selected (Fig. 1b).

Maximum-likelihood $b$-values were calculated using the ZMAP software package (Wiemer 2001). The magnitude of completeness, $M_{c}$, the lowest magnitude for which the observed frequency-magnitude relationship follows a power law, was first determined. $M_{c}$ tends to increase from the coast toward the trench in the case of subduction zones in Japan (e.g., Nanjo et al. 2010; Schorlemmer et al. 2018). Using the maximum curvature method (Wiemer and Wyss 2000), the spatial distribution of $M_{c}$ was estimated using a sampling radius of $35 \mathrm{~km}$ with a horizontal grid spacing of $0.1^{\circ}$ for each grid node (e.g., Chiba 2019), which represents the optimal radius value for $b$-value calculation in this study, as discussed below. $M_{c}$ varies across the study region, with $M_{c} \leq 1.4$ for large areas (Fig. 2). Therefore, 12,090 events with $M \geq$ 1.4 were selected for further analysis (Fig. 1). $M_{c}$ is relatively high in the Hyuga-nada region owing to the sparsity of observation networks. Using the goodness-of-fit methods of Wiemer and Wyss (2000), it was found that more than $90 \%$ of the variability in the observed frequency-magnitude relationship can be explained by a power law. Using a horizontal grid spacing of $0.1^{\circ} \times 0.1^{\circ}$, a spatial $b$-value map was constructed by maximum-likelihood methods, as follows:

$$
b=\log e /\left(M_{\text {mean }}-M_{0}\right),
$$

where $M_{\text {mean }}$ is the mean magnitude, and $M_{0}=M_{c}-0.05$ for magnitude bins with constant widths of 0.1 (Aki 1965). The local $M_{c}$ was calculated at each grid node for the catalog with $M \geq 1.4$ events. The optimal sampling radius, which corresponds to the largest radius that allows the most detailed resolution of $b$-value heterogeneities, must be determined to map $b$-values by extracting events around each grid point (Schorlemmer et al. 2004). From $b$-value maps constructed using different sampling radii, the patterns of $b$-value distribution seem visually identical when sampled at radii of 30 to $40 \mathrm{~km}$ (Fig. 3). A sampling radius of $35 \mathrm{~km}$ was therefore used in this study.

The maximum curvature method often underestimates $M_{c}$ on average by 0.2 magnitude unit for gradually curved frequency magnitude distributions that stem from spatial and/or temporal heterogeneities (Woessner and Wiemer 2005). In addition to this concern, the number of earthquakes is relatively low in central Shikoku (Fig. 1), and $M_{c}$ is relatively high in the Hyuga-nada region (Fig. 2). It is thus necessary to assess whether the similar $b$-value distribution is also obtained for catalogs with $M_{c}>1.4$, especially for central Shikoku and Hyuga-nada regions.

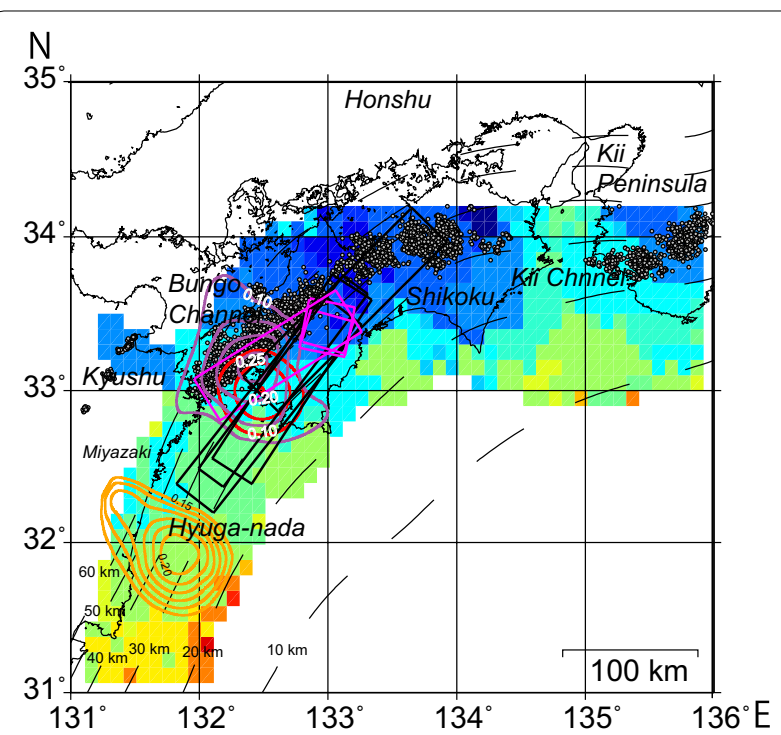

Fig. 2 Spatial distribution of catalog completeness magnitude, $M_{c}$, estimated using the maximum curvature method (Wiemer and Wyss 2000) on a grid with $0.1^{\circ}$ horizontal spacing. Events were extracted in a $35-\mathrm{km}$ radius around each node. Purple and red contours represent isoslip values due to 2003 and 2010 SSEs in the Bungo Channel (Ozawa et al. 2013; Ozawa 2017), with labels in meters and an increment of $0.05 \mathrm{~m}$. Orange contours represent the cumulative slip distribution due to 1997, 2005, 2007, and 2009 SSEs in southern Miyazaki district (Yarai and Ozawa 2013), with labels in meters and an increment of $0.01 \mathrm{~m}$. Purple and black rectangles represent faults corresponding to SSEs from 2004-2006 to 2011-2013 in western Shikoku (Takagi et al. 2016). Gray circles show LFE locations obtained from the JMA catalog

Spatial $b$-value distributions were constructed for $M_{c}=1.5,1.6$, and 1.7, respectively. The horizontal grid spacing of $0.1^{\circ}$ for each grid node is the same as that for $M_{c}=1.4$. The sampling radiuses to extract events around each node were set to 35 and $50 \mathrm{~km}$, respectively, because of the decreased number of the earthquakes used for the analysis due to increased $M_{c}$. In the $b$-value calculation, the local $M_{c}$ was calculated at each grid node, as mentioned above. The resulting $b$-value distributions for the catalogs with higher $M_{c}$ were similar to those obtained using $M_{c}=1.4$ in the whole area, including central Shikoku and Hyuga-nada regions (Additional file 1: Fig. S1). It is therefore considered that the spatial $b$-value distribution for the catalog with $M_{c}=1.4$ was robustly estimated in the whole region. On the other hand, a plane $b$-value map is only considered in the present study, although the $b$-value distribution may change vertically within the plate. Chiba (2019) has already revealed that the plane $b$-value distribution reflects the average stress and/or strength states within the plate in the area encompassing the Bungo Channel and Hyuga-nada regions, corresponding to lines $1-1^{\prime}$ and $2-2^{\prime}$ in Fig. 1 . It is thus 
a

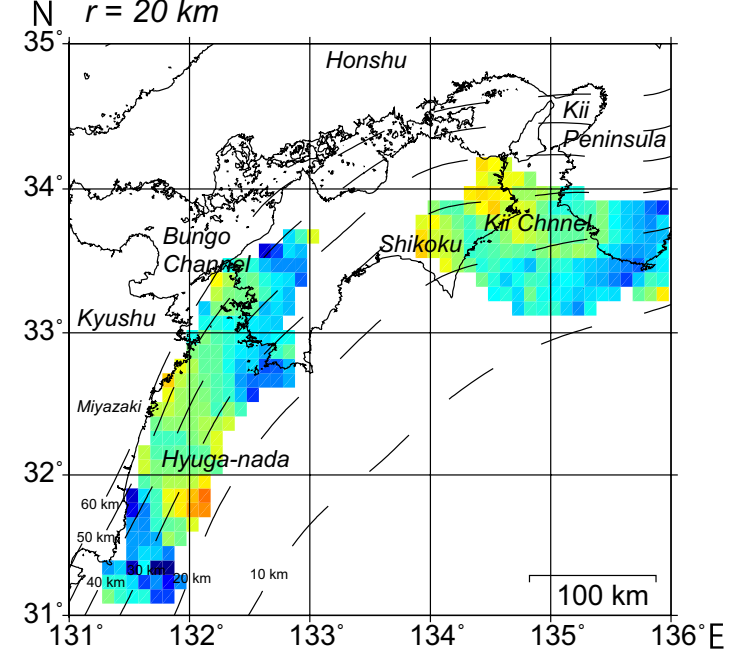

C N $r=35 \mathrm{~km}$

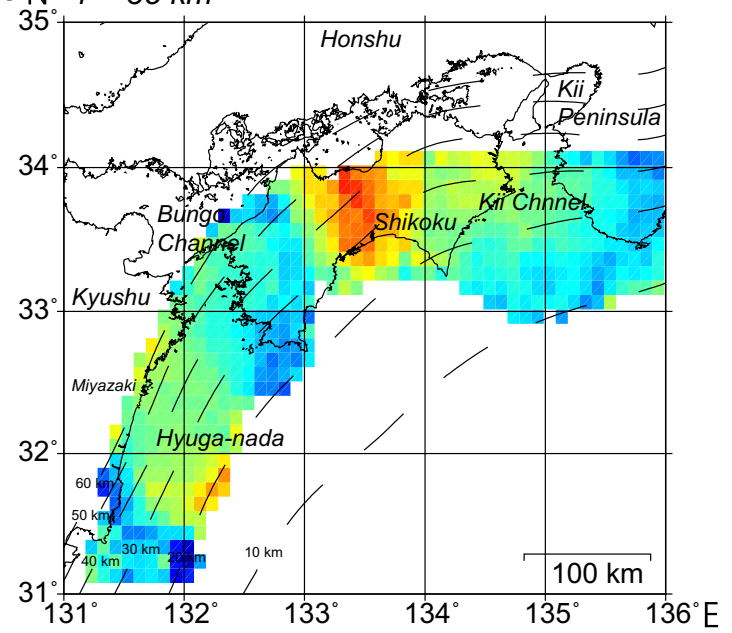

b $_{\mathrm{N}} r=30 \mathrm{~km}$

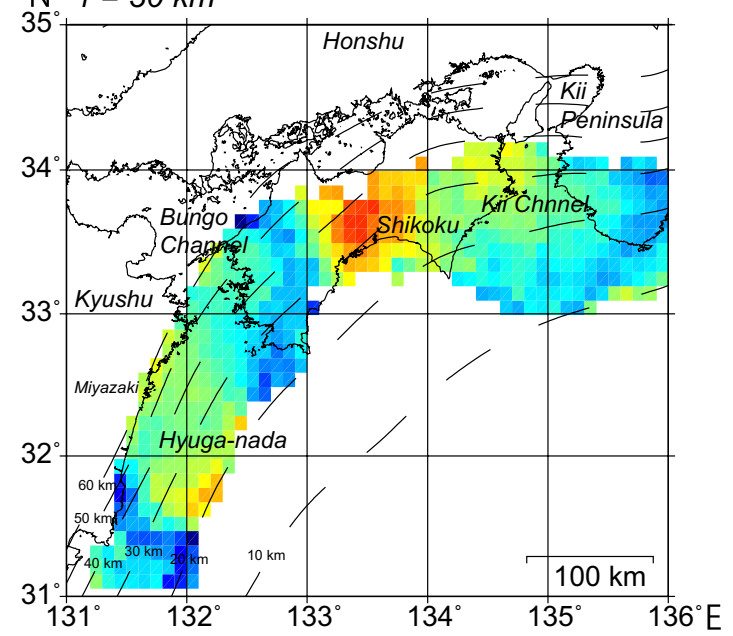

d N $r=40 \mathrm{~km}$

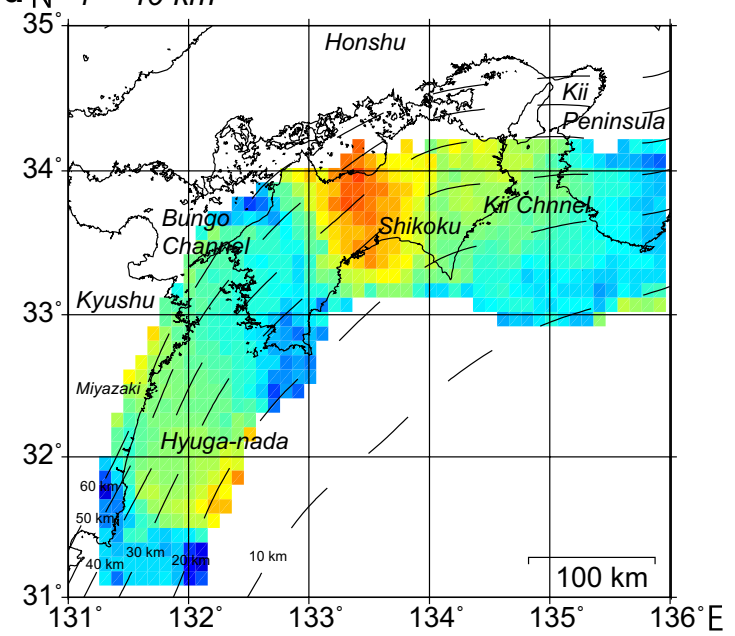

$\mathbf{e}_{\mathrm{N}} r=50 \mathrm{~km}$
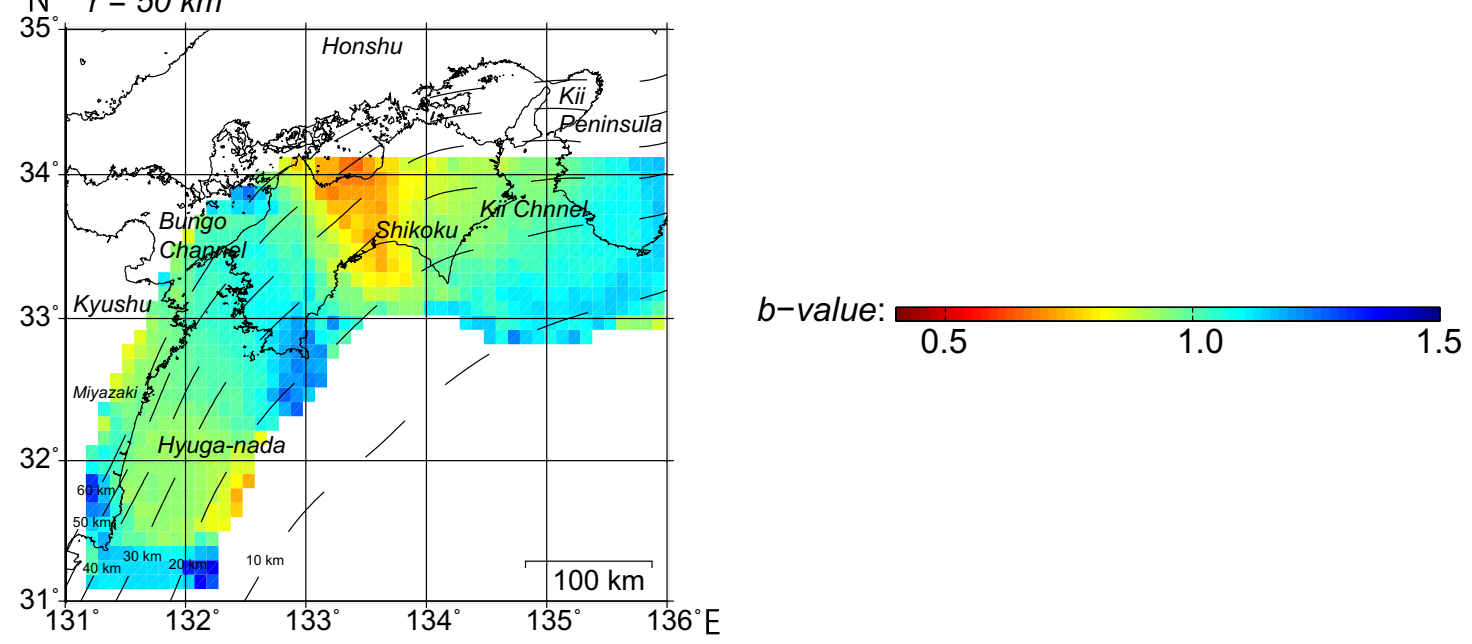

Fig. $3 b$-value maps for different sampling radii: $\mathbf{a} r=20 \mathrm{~km} ; \mathbf{b} r=30 \mathrm{~km} ; \mathbf{c} r=35 \mathrm{~km} ; \mathbf{d} r=40 \mathrm{~km} ; \mathbf{e} r=50 \mathrm{~km}$. $\mathbf{c}$ Data were used in the subsequent analysis. If fewer than 50 events were located within the search radius of a grid node, the corresponding $b$-value was not mapped 
necessary to assess whether $b$-values do not vary vertically within the plate in the area encompassing central Shikoku and Kii regions significantly. The $b$-value distributions were calculated along two transects (lines 3-3' and 4-4') in the focal region. Using the method of Schorlemmer et al. (2004), the $b$-value cross sections were constructed using a $1-\mathrm{km}$ spacing grid and constant sampling radiuses of $23 \mathrm{~km}$ (line 3-3') and $8 \mathrm{~km}$ (line 4-4') for the events located within $50 \mathrm{~km}$ of each transect. It was found that the resulting $b$-value distributions do not vary vertically within the plate in both lines significantly (Additional file 1: Fig. S2). The plane $b$-value map in the present study is therefore considered to reflect the average in-plate stress and/or strength states along the plate interface.

\section{Results and discussion}

The spatial distribution of $b$-values is shown in Fig. 4, with LFEs and slip distributions of long-term SSEs being superimposed on this map. The basic characteristics of the $b$-value distribution in the area comprising the Bungo Channel and Hyuga-nada regions are approximately the same as those in Chiba (2019), although the resolution is inferior to that of the earlier study owing to the narrow depth range of extracted events and coarser grid spacing. $b$-values are moderate to low $(b=0.6-1.1)$ in regions with significant slip because of long-term SSEs in

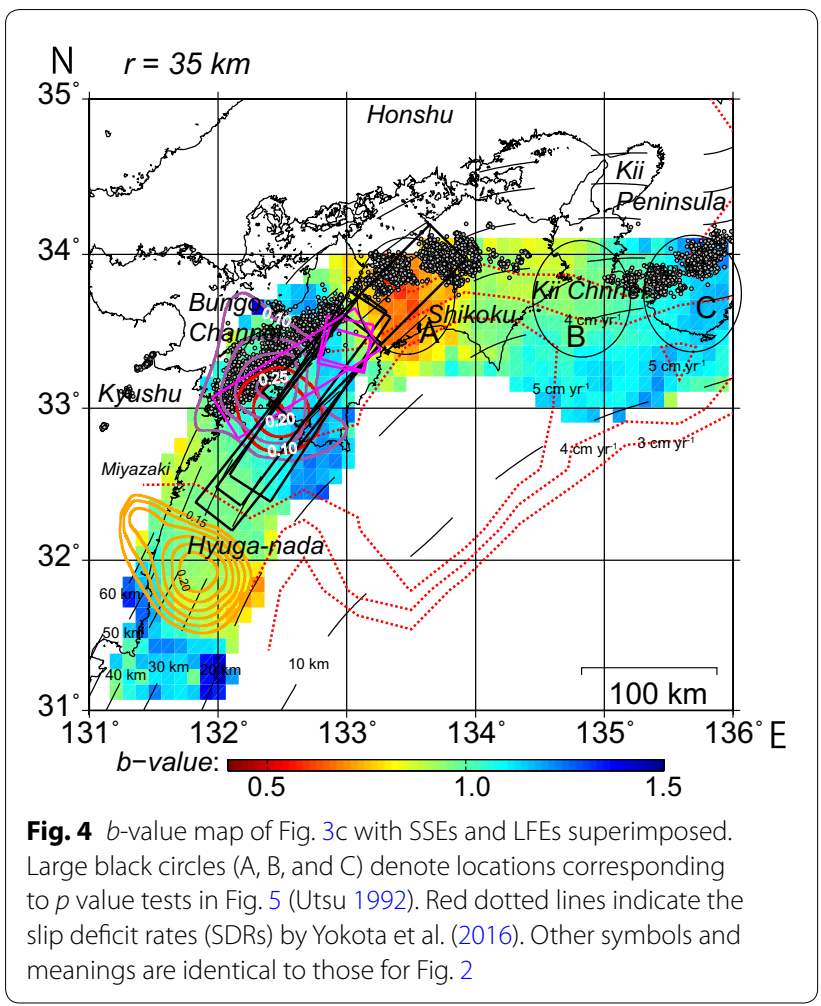

this area during the studied time window. $b$-values in the Bungo Channel, where LFEs occur, are higher than those in the Hyuga-nada region, where no LFEs have been detected. Chiba (2019) focused on a detailed discussion of $b$-values in the narrow area encompassing the Bungo Channel and Hyuga-nada regions, whereas the present study focuses on the comprehensive characteristics of the $b$-value distribution in the western Nankai Trough. $b$-values vary along the strike direction of the subducting plate in the Nankai Trough. $b$-values are relatively high in the Kii Peninsula, western Shikoku, and the southern Hyuganada regions. In contrast, $b$-values in the gaps between these regions are low to moderate. $b$-values are noticeably low ( 0.6) in central Shikoku district.

Analysis of $p$ values was performed to evaluate the statistical significance of $b$-value heterogeneities, using

$$
p=e^{(-d A / 2-2)},
$$

where

$$
\begin{aligned}
\mathrm{dA}= & -2 N \ln (N)+2 N_{1} \ln \left(N_{1}+N_{2} b_{1} / b_{2}\right) \\
& +2 N_{2} \ln \left(N_{1} b_{2} / b_{1}+N_{2}\right),
\end{aligned}
$$

where $N_{1}$ and $N_{2}$ are the number of events in each group compared, and $N=N_{1}+N_{2}$ (Utsu 1992). $b$-value heterogeneities have already been shown to be statistically significant in the area encompassing the Bungo Channel and Hyuga-nada regions (Chiba, 2019). In the present study, $b$-value heterogeneities were evaluated for the central Shikoku district (region A), Kii Channel (region B), and Kii Peninsula regions (region $\mathrm{C}$ ) (indicated by black circles in Fig. 4). Regions $B$ and $C$ correspond approximately to the source regions of SSEs and LFEs, respectively (e.g., Kobayashi 2014; Geospatial Information Authority of Japan 2016; Obara and Kato 2016). A value of $p=1.92 \times 10^{-10}$ is obtained between regions $\mathrm{A}$ and $\mathrm{B}$ and $p=1.55 \times 10^{-5}$ between regions $\mathrm{B}$ and $\mathrm{C}$; thus, the null hypothesis that these regions have identical $b$-values can be rejected at a confidence level of $>99 \%$ (Fig. 5a, b). Interestingly, the central Shikoku district, with low $b$-values, corresponds to a source region of LFEs, whereas other regions with LFEs correspond roughly to regions of high $b$-values. On the other hand, $b$-values are moderate to low in the Kii Channel area, where SSEs did not occur during the period between October 2000 and December 2012 (e.g., Kobayashi 2014; Geospatial Information Authority of Japan 2016; Ozawa 2017). This is similar to the northern Miyazaki district between the Bungo Channel and Hyuga-nada regions, which also recorded no SSEs during this time frame (Ozawa et al. 2001; Ozawa 2017; Chiba 2019). The characteristics of the $b$-values associated with the occurrence of SSEs and LFEs in each region in the present study are summarized in Table 1. 

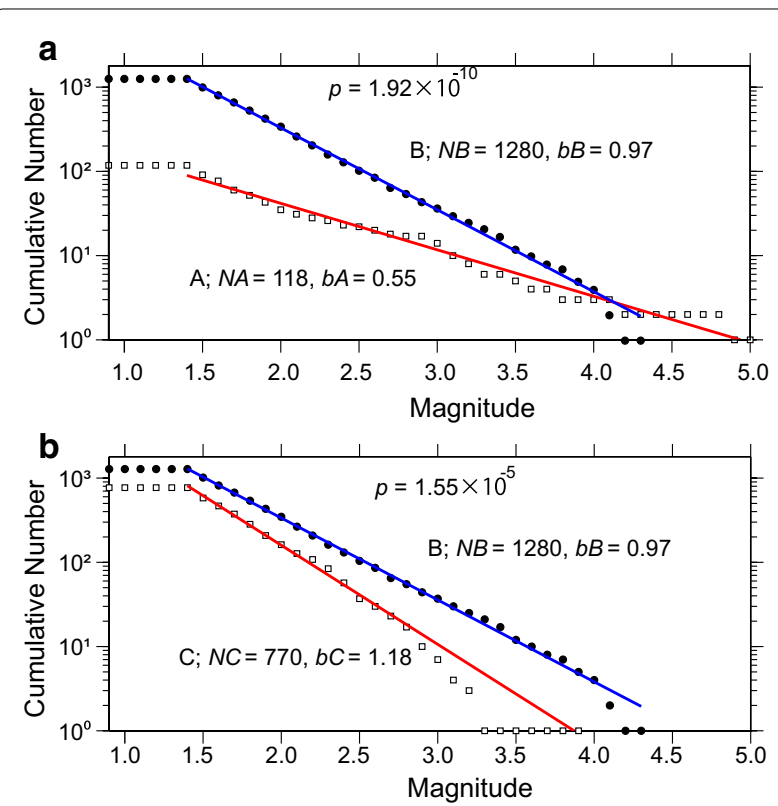

Fig. 5 a $p$-value test comparing a region of low $b$-values in central Shikoku district (region A, Fig. 4) with a region of moderate $b$-values in the Kii Channel (region B, Fig. 4). b $p$-value test comparing a region of high $b$-values in the Kii Peninsula (region C, Fig. 4) with a region of moderate $b$-values in the Kii Channel (region B, Fig. 4)

The $b$-value distribution obtained in this study seems to correlate with the occurrence of LFEs, except for the low $b$-values in central Shikoku. $b$-values in regions with SSEs but no LFEs (Kii Channel, northern Miyazaki, and Hyuga-nada) are relatively lower than those in regions with SSEs and LFEs (western Shikoku and Bungo Channel), except for central Shikoku. LFEs and SSEs are considered to be induced by a common generation model, that is, the increased pore-fluid pressure due to dehydration from the subducting plate (e.g., Matsubara et al. 2009). On the other hand, measurable stress accumulation and release are also likely to have occurred in regions with SSEs due to relatively large slip accompanying the SSEs. For example, $b$-values in the Bungo Channel region where large SSEs have occurred are relatively higher than those in other regions with SSEs. The dependent characteristics of $b$-values on LFEs and SSEs must be thus considered simultaneously. The potential causes of these $b$-value heterogeneities are discussed below with reference to the stress- and strength-dependent characteristics of LFEs and SSEs.

$b$-values, as shown, vary spatially along the strike direction of the subducting plate in the Nankai Trough. Among the heterogeneities of the $b$-value distribution, $b$-values are noted to be low in central Shikoku district, but the slip contribution of SSEs there is small. Chiba (2019) discussed the effects of LFEs on the $b$-value distribution with respect to the LFE generation mechanism of Nakajima and Hasegawa (2016): In this model, LFEs occur in regions with undrained conditions above the plate interface because the impermeable overlying plate increases pore-fluid pressure along the plate interface and reduces shear strength. However, regions with no LFEs require well-drained conditions in the overlying plate; this drainage regime does not trap fluids liberated from the subducting slab near the plate interface and reduces pore-fluid pressure, resulting in higher shear strength. According to this model, therefore, the source regions of LFEs should correspond to areas with high $b$-values, but many LFEs occur in central Shikoku district, which is characterized by low $b$-values, in contrast to other LFE source regions, such as the Kii Peninsula, western Shikoku, and the Bungo Channel. These results imply that the low $b$-values in central Shikoku require a different (or additional) physical source than generation of LFEs. Matsubara et al. (2009) estimated a seismic velocity structure in and around the subducting plate beneath southwestern Japan. According to this study, the $V_{P} / V_{S}$ around the

Table 1 The characteristics of $\boldsymbol{b}$-values, LFEs, and SSEs activities in each region

\begin{tabular}{|c|c|c|c|}
\hline Region & LFE activity & SSE activity-size & $b$-value \\
\hline Kii Peninsula & O & $x$ & High $(b \sim 1.2)$ \\
\hline Kii Channel & $x$ & $\begin{array}{l}\text { (but, not during the analysis period) - } \\
\text { Medium }\left(M_{w} 6.6-6.7\right)\end{array}$ & Moderate $(b \sim 1.0)$ \\
\hline Central Shikoku & O & O very small $\left(M_{w} 6.0-6.3\right)$ & $\operatorname{Low}(b \sim 0.6)$ \\
\hline Western Shikoku & O & O small (Mw 6.0-6.3) & High $(b \sim 1.2)$ \\
\hline Bungo Channel & O & $\bigcirc$ Large $\left(M_{w} 7.0-7.1\right)$ & High $(b \sim 1.2)$ \\
\hline Northern Miyazaki & $x$ & $\begin{array}{l}\text { (but, not during the analysis period) - } \\
\text { medium }\left(M_{w} \sim 6.5\right)\end{array}$ & Moderate $(b \sim 1.0)$ \\
\hline Hyuga-nada & $x$ & Medium $\left(M_{w} \sim 6.7\right)$ & Moderate to low $(b \sim 0.8)$ \\
\hline
\end{tabular}

The magnitude size of the SSEs is based on the following studies: (1) Kii Channel (Kobayashi 2014; Geospatial Information Authority of Japan 2016); (2) west to central Shikoku (Takagi et al. 2016); (3) Bungo Channel (Ozawa et al. 2013; Ozawa 2017); (4) northern Miyazaki (Ozawa et al. 2001); and (5) Hyuga-nada regions (Yarai and Ozawa 2013) 
plate interface in central Shikoku seems to be smaller than that in other regions with LFEs. They suggested that high- $V_{P} / V_{S}$ zones around the plate interface are generated due to the dehydration of fluid from the subducting plate and that LFEs occur due to the increased pore pressure along the plate interface. Kita and Matsubara (2016) estimated a seismic attenuation structure $\left(\mathrm{Q}_{P}\right)$ beneath Shikoku and Kii peninsula. The $\mathrm{Q}_{P}$ in the central Shikoku seems to be relatively high in the oceanic crust of the subducting plate as well as in the overlying plate. Highand low- $Q_{P}$ structures are regarded as impermeable barrier and fluid rich areas, respectively (Kita and Matsubara 2016). The results of these studies imply that the amount of fluid leakage to the overlying plate in central Shikoku is smaller than that in other regions with LFEs. Subsequently, pore-fluid pressure is considered to be relatively low along the plate interface in the focal region, resulting in relatively high shear strength (lower $b$-value). Indeed, the number of LFEs in central Shikoku is smaller than that in other regions with LFEs in the present study (e.g., Nakajima and Hasegawa 2016). The low $b$-values and decreased number of LFEs in the focal region may be related to the small amount of fluid leakage to the overlying plate.

On the other hand, two SSEs with magnitudes $M_{w}=6.0-6.3$ (in 2004-2006 and 2011-2013) occurred in western to central Shikoku district during the study period (Takagi et al. 2016). The approximate rupture area of the SSE in 2011-2013 extends into the low $b$-value region of central Shikoku discussed here (e.g., Figure 4) and is longer than the 2004-2006 SSE (Takagi et al. 2016). Slip due to these SSEs is concentrated mainly in western Shikoku, which means that more shear stress is released there. On the contrary, it is expected that considerable shear stress has accumulated in central Shikoku where the slip due to these SSEs was small. Takagi et al. (2016) pointed out a possibility that the slip migrates eastward after the occurrence of the 2003 and 2010 SSEs in the Bungo Channel, resulting in the SSEs in western to central Shikoku. Kobayashi (2010) also suggested that a small long-term SSE, which is identical to part of the 2004-2006 SSE estimated by Takagi et al. (2016), occurred in 2005 in western Shikoku and is located in the extension part of the occurrence region of the 2003 SSE in the Bungo Channel. Ozawa et al. (2007) estimated that the 2003 SSE started in the southern part of the Bungo Channel and subsequently expanded to the northern part of the Bungo Channel and the southwestern part of Shikoku. The occurrence of a series of the SSEs with the migration toward central Shikoku may produce substantial stress loading in the focal region, resulting in the low $b$-values. In addition, ordinary earthquakes are uncommon in central Shikoku (Fig. 1); thus, these findings might have implications for stress accumulation. The relationship between $b$-values and interplate slip deficit rates (SDRs) along the Nankai Trough can also be used to infer the stress state related to plate coupling. In the SDR distributions of Yokota et al. (2016), an area with high SDR ( $>3 \mathrm{~cm}_{\text {year }}{ }^{-1}$ ) appears to protrude on the downdip side of the plate interface in central Shikoku (Fig. 4). It is therefore likely that stress accumulation in this region is relatively high. From these relationships between $b$-values and the above-mentioned studies, the significant low $b$-value anomaly in central Shikoku is considered to reflect the high shear strength resulting from the small amount of fluid leakage around the plate interface, and the stress accumulation accompanying the occurrence of a series of the SSEs with the migration toward central Shikoku.

The above discussion of the dependence of stress and strength on LFEs and SSEs improves our understanding of the causes of $b$-value heterogeneity in the Bungo Channel and Hyuga-nada regions. SSEs have occurred in both the Bungo Channel and Hyuga-nada regions, but the magnitudes of SSEs in the Bungo Channel in $2003\left(M_{w} 7.1\right)$ and $2010\left(M_{w} 7.0\right)$ are larger than those in the Hyuga-nada region in 2005, 2007, and $2009\left(\sim M_{w} 6.7\right)$ (e.g., Ozawa 2017); the total moment release due to SSEs in the Bungo Channel is therefore greater. The corresponding energy release is $10^{4.8+1.5 \times 7.1}+10^{4.8+1.5 \times 7.0} \sim 4.81 \times 10^{15}[\mathrm{~J}]$ in the Bungo Channel and $3 \times 10^{4.8+1.5 \times 6.7} \sim 2.12 \times 10^{15}[\mathrm{~J}]$ in the Hyuga-nada region, which can be computed using the equation $\log E=4.8+1.5 M$, where $E$ is energy in Joules and $M$ is magnitude (Kanamori 1977; Hanks and Kanamori 1979). $b$-values in the Bungo Channel are higher than in the Hyuga-nada region, although SDRs in the former region are higher (Yokota et al. 2016). Therefore, stress released by SSEs must also be considered when investigating the cause of the high $b$-values in the Bungo Channel. On the other hand, Matsubara et al. (2009) estimated that the high- $V_{P} / V_{S}(1.84-1.88)$ area is elongated shallower seaward in the Bungo Channel region. The location of this high $-V_{P} / V_{S}$ area approximately corresponds to the high $b$-value area that extends shallower seaward in the Bungo Channel region (Fig. 4). Matsubara et al. (2009) pointed out that the high- $V_{P} / V_{S}$ areas extend seaward shallowly in regions with SSEs, such as the Bungo Channel and Tokai regions, whereas the high $-V_{P} / V_{S}$ areas do not extend seaward shallowly in regions with no SSEs. This suggests that a large amount of fluid is dehydrated from the subducting plate in regions with LFEs and SSEs, compared to regions with LFE activity but no SSEs. The local high $b$-values in the focal region are also ascribed to a decrease in shear strength resulting from the dehydration of fluid that extends shallower seaward due to the large amount of fluid along the 
plate interface. The high $b$-values in the Bungo Channel region are thus considered to reflect complicated stress and strength perturbations due to a partial release of the accumulated stress by large SSEs, and the decrease in shear strength along the plate interface resulting from the dehydration of fluid that extends shallower seaward. These points were not substantially discussed by Chiba (2019).

The interpretation of $b$-value heterogeneities in regions with only one class of slow earthquake is more straightforward. The Kii Channel is a source region of SSEs, but SSEs did not occur during the analysis window (e.g., Kobayashi 2014; Geospatial Information Authority of Japan 2016; Ozawa 2017). The moderate-to-low $b$-values of the Kii Channel reflect a high differential stress because of the lack of SSEs. The same interpretation explains the northern Miyazaki district between the Bungo Channel and Hyuga-nada regions, which similarly lacked SSEs (Ozawa et al. 2001; Ozawa 2017; Chiba 2019). The high $b$-values in the Kii Peninsula, which has only LFE activity, can be explained by the LFE model of Nakajima and Hasegawa (2016). Indeed, the high- $V_{P} / V_{S}(1.80 \sim 1.83)$ zone, which is the indicator of the large amount of fluid due to the dehydration of fluid from the subducting plate, is estimated around the plate interface beneath the Kii Peninsula (Matsubara et al. 2009).

\section{The relationship between $b$-values and Nankai megathrust earthquakes}

The relationship between slow earthquake generation and megathrust earthquakes has key implications for seismic hazard assessment because stress transfer due to slow earthquakes increases the probability of triggering a huge earthquake on adjacent megathrust source faults (Obara and Kato 2016). The updip side of the plate in central to eastern Shikoku district corresponds to the region that underwent the greatest slip during the 1946 Nankai earthquake (Ando 1975). The $b$-values in the focal area are not necessarily low, although the area covered by the $b$-value distribution is small owing to the lack of events on the updip side. Nanjo and Yoshida (2018) examined $b$-values in a wider area in and around the Nankai Trough using the JMA unified catalog. $b$-values in the focal region of the Nankai earthquake were higher than those in the source regions of LFEs on the downdip side of the plate, although $b$-values in the focal region of the Nankai earthquake were relatively small (Nanjo and Yoshida 2018, Fig. 1). The asperity areas of huge earthquakes often have low $b$-values (e.g., Schorlemmer and Wiemer 2005; Ghosh et al. 2008; Enescu et al. 2011), but the $b$-value distribution in the focal region of the Nankai megathrust earthquake is more complicated. Before the
2011 Tohoku earthquake, slow earthquakes occurred in and around the potential future focal region at different timescales. Yokota and Koketsu (2015) found that a longterm transient took place over the 9 years preceding the Tohoku earthquake in the deepest part of the mainshock rupture area. Ito et al. (2013) detected two SSEs over a period of 1 week to several months in 2008 and 2011 near the mainshock rupture area. Kato et al. (2012) found two SSEs that migrated toward the initial rupture point of the Tohoku earthquake during foreshock activity; these SSEs produced substantial stress loading in what became the Tohoku rupture area. In addition, it is well known that $b$-values decrease in the asperity area prior to a huge earthquake (e.g., Nanjo et al. 2012). These various findings imply that a unified analysis of $b$-values in the rupture regions of both slow earthquakes (SSEs and LFEs) and huge megathrust earthquakes is necessary to estimate the hazard associated with future megathrust earthquakes.

For the focal region with low $b$-values, one possible scenario that could explain the observed temporal changes in $b$-values associated with the occurrence of the Nankai megathrust earthquake is the following: (1) Slow earthquakes are generated in the downdip region and adjacent areas in the asperity area (e.g., in central Shikoku district for the Nankai earthquake), releasing stress and subsequently increasing the local $b$-value in the occurrence region of these slow earthquakes. (2) The stress released by these slow earthquakes is transferred to the asperity area, and shear stress increases locally, decreasing the $b$-value in the asperity area. This scenario is consistent with both the stress-dependent characteristics of LFEs and SSEs and the relationship between slow earthquake generation and megathrust earthquakes. Monitoring spatiotemporal changes in $b$-values might therefore be an effective tool for improving seismic hazard assessment at subduction zones with slow earthquake activity.

\section{Conclusions}

In this study, a regional $b$-value distribution for the western Nankai Trough was presented, showing that $b$-values vary along the strike direction of the subducting plate. $b$-values are very low $(b \sim 0.6)$ in central Shikoku district, where LFEs frequently occur; however, $b$-values in other regions with frequent LFEs are generally high. The low $b$-values in central Shikoku cannot be explained by the preferred model for LFE generation. The $V_{P} / V_{S}$ and $\mathrm{Q}_{P}$ around the plate interface in central Shikoku estimated from seismic velocity and attenuation structure are relatively lower and higher than those in other regions with LFEs, respectively. These observations may reflect the high shear strength state in the central Shikoku due to 
the small amount of fluid leakage around the plate interface, compared with other regions with LFEs. Meanwhile, SSEs occurred in western to central Shikoku during the study period, and the slip that they generated in central Shikoku was relatively small. Furthermore, a series of the SSEs in the focal region migrates toward the central Shikoku. These observations imply that considerable shear stress has accumulated there. The effects of strength and stress perturbations in the source regions of slow earthquakes must be considered if the causes of the observed $b$-value heterogeneities are to be understood. This also improves our understanding of how $b$-values relate to stress-dependent characteristics of SSEs and LFEs in the Bungo Channel and Hyuga-nada regions. In addition, $b$-values are moderate to low in regions with SSEs but no LFEs, whereas with the exception of central Shikoku, $b$-values are high in regions with LFEs but no SSEs. These findings imply that the spatial distribution of $b$-values in the megathrust area of Nankai Trough reflects the porefluid pressure states along the plate interface associated with the occurrence of LFEs and the stress accumulation and release by SSEs. On the other hand, $b$-values in the region that underwent the greatest slip during the 1946 Nankai earthquake are not necessarily lower than those in the source regions of downdip SSEs and LFEs. Whereas the asperity areas of huge earthquakes are characterized by low $b$-values, the $b$-value distribution in the Nankai megathrust area is more complicated. A unified analysis of $b$-values in the source regions of slow earthquakes and megathrust earthquakes may be an important tool for monitoring impending megathrust earthquakes, as the stress-dependent characteristics of LFEs and SSEs and the relationship between slow earthquakes and megathrust earthquakes clearly need to be considered.

\section{Supplementary information}

Supplementary information accompanies this paper at https://doi. org/10.1186/s40623-020-1130-7.

Additional file 1. Additional figures.

\section{Acknowledgements}

The author used data from the Japan Unified high-resolution relocated Catalog for Earthquakes (JUICE), compiled by Yano et al. (2017) (http://www.hinet .bosai.go.jp/topics/JUICE/?LANG=en), the unified earthquake catalog of the Japan Meteorological Agency (JMA) (https://www.data.jma.go.jp/svd/egev/ data/bulletin/index.html), long-term slow-slip event models provided by Dr. Shinzaburo Ozawa of the Geospatial Information Authority of Japan (GSI), and the Slow Earthquake Database (http://www-solid.eps.s.u-tokyo.ac.jp/ slowe $\mathrm{q} /$ ? page $=$ map). $b$-value analysis was performed using the MATLAB software package ZMAP (Wiemer 2001) (http://www.seismo.ethz.ch/static/stat_2010_ website/stat-website-pre2010/www.earthquake.ethz.ch/software/zmap.html). Figures are prepared using GMT (Wessel and Smith 1995). This study was partially funded by the Institute of Seismology and Volcanology, Faculty of Science, Kyushu University, Japan. The author thanks the Editor David Shelly and two anonymous reviewers for helping to improve the manuscript.

\section{Authors' contributions}

$\mathrm{KC}$ conducted the $b$-value analyses and the interpretation of the results and drafted the manuscript. The author read and approved the final manuscript.

\section{Funding}

This study was partially funded by the Institute of Seismology and Volcanology, Faculty of Science, Kyushu University.

\section{Availability of data and materials}

The data used in this study are available at the Data Management Center of NIED (http://www.hinet.bosai.go.jp/topics/JUICE/?LANG=en) and JMA (https ://www.data.jma.go.jp/svd/eqev/data/bulletin/hypo.html).

Ethics approval and consent to participate

Not applicable.

\section{Consent for publication}

Not applicable.

\section{Competing interests}

The author declares no competing interests.

Received: 28 August 2019 Accepted: 2 January 2020

Published online: 10 January 2020

\section{References}

Aki K (1965) Maximum likelihood estimate of $b$ in the formula $\log N=a-b M$ and its confidence limits. Bull Earthquake Res Inst Tokyo Univ 43:237-239

Ando M (1975) Source mechanisms and tectonic significance of historical earthquakes along the Nankai trough, Japan. Tectonophysics 27(2):119140. https://doi.org/10.1016/0040-1951(75)90102-X

Chao K, Peng Z, Gonzalez-Huizar H, Aiken C, Enescu B, Kao H, Velasco AA, Obara K, Matsuzawa T (2013) Global search of triggered tremor following the $2011 \mathrm{M}_{\mathrm{w}} 90$ Tohoku-Oki earthquake. Bull Seismol Soc Am 103(2B):1551-1571. https://doi.org/10.1785/0120120171

Chiba K (2019) Spatial and temporal distributions of b-values related to longterm slow-slip and low-frequency earthquakes in the Bungo Channel and Hyuga-nada regions, Japan. Tectonphysics 757:1-9. https://doi. org/10.1016/j.tecto.2019.02.021

Enescu B, Enescu D, Ito K (2011) Values of b and p: their variations and relation to physical processes for earthquakes in Japan and Romania. Rom J Phys 56:590-610

Frohlich C, Davis S (1993) Teleseismic b values; or, much ado about 1.0. J Geophys Res 98(B1):631-644

Geospatial Information Authority of Japan (2016) Crustal movements in the Kinki district, Japan. Coord Commit Eq Pred 95:296

Ghosh A, Newman AV, Thomas AM, Farmer GT (2008) Interface locking along the subduction megathrust from $b$-value mapping near Nicoya Peninsula, Costa Rica. Geophys Res Lett 24:L01301. https://doi. org/10.1029/2007GL031617

Gutenberg B, Richter CF (1944) Frequency of earthquakes in California. Bull Seismol Soc Am 34:185-188

Hanks T, Kanamori H (1979) A moment-magnitude scale. J Geophys Res 98:2348-2352

Hayes GP, Moore GL, Portner DE, Hearne M, Flamme H, Furtney M, Smoczyk GM (2018) Slab2: a comprehensive subduction zone geometry model. Science 362(6410):58-61. https://doi.org/10.1126/science.aat4723

Ide S, Shelly DR, Beroza GC (2007) Mechanism of deep low-frequency earthquakes: further evidence that deep non-volcanic tremor is generated by shear slip on the plate interface. Geophys Res Lett 34:L03308. https://doi. org/10.1029/2006GL028890

Ishimoto M, lida K (1939) Observations sur les seisms enregistré par le microseismograph construit demiement. Bull Earthq Res Inst Tokyo Univ $17: 443-478$

Ito Y, Hino R, Kido M, Fujimoto H, Osada Y, Inazu D, Ohta Y, linuma T, Ohzono M, Miura S, Mishina M, Suzuki K, Tsuji T, Ashi J (2013) Episodic slow slip events in the Japan subduction zone before the 2011 Tohoku-Oki earthquake. Tectonophysics 600:14-26. https://doi.org/10.1016/j.tecto .2012.08.022 
Kanamori H (1977) The energy release in great earthquakes. J Geophys Res 82:2981-2987

Kaneda Y, Kawaguchi K, Araki E, Matsumoto H, Nakamura T, Kamiya S, Ariyoshi K, Hori T, Baba N, Takahashi N (2015) Development and application of an advanced ocean floor network system for megathrust earthquakes and tsunamis. In: Favali P et al (eds) Seafloor observatories. Springer, Berlin, pp 643-662. https://doi.org/10.1007/978-3-642-11374-1_25

Kato A, Obara K, Igarashi T, Tsuruoka H, Nakagawa S, Hirata N (2012) Propagation of slow slip leading up to the $2011 \mathrm{M}_{w} 9.0$ Tohoku-Oki earthquake. Science 335:705-708

Kita S, Matsubara M (2016) Seismic attenuation structure associated with episodic tremor and slip zone beneath Shikoku and Kii peninsula, southwestern Japan, in the Nankai subduction zone. J Geophs Res 121:19621982. https://doi.org/10.1002/2015JB102493

Kobayashi A (2010) A small scale long-term slow slip occurred in the western Shikoku in 2005. J Seismol Soc Jpn 63:97-100 (in Japanese with English abstract)

Kobayashi A (2014) A long-term slow slip from 1996 to 1997 in the Kii Channel, Japan. Earth Planets Space 66:9. https://doi.org/10.1186/1880-5981-66-9

Matsubara M, Obara K, Kasahara K (2009) High- $V_{p} / V_{s}$ zone accompanying non-volcanic tremors and slow-slip events beneath southwestern Japan. Tectonophysics 472:6-17. https://doi.org/10.1016/j.tecto.2008.06.013

Matsumura S (1997) Focal zone of a future Tokai earthquake inferred from the seismicity pattern around the plate interface. Tectonophysics 273:271-291

Mogi K (1962) Magnitude-Frequency relation for elastic shocks accompanying fractures of various materials and some related problems in earthquakes. Bull Earthq Res Inst Tokyo Univ 40:831-853

Nakajima J, Hasegawa A (2016) Tremor activity inhibited by well-drained conditions above a megathrust. Nat Commun 7:13863. https://doi. org/10.1038/ncomms13863

Nanjo KZ, Yoshida A (2018) A b map implying the first eastern rupture of the Nankai Trough earthquakes. Nat Commun 9:1117. https://doi. org/10.1038/s41467-018-03514-3

Nanjo KZ, Ishibe T, Tsuruoka D, Schorlemmer D, Ishigaki Y, Hirata N (2010) Analysis of the completeness magnitude and seismic network coverage of Japan. Bull Seismol Soc Am 100(6):3261-3268. https://doi. org/10.1785/0120100077

Nanjo KZ, Hirata N, Obara K, Kasahara K (2012) Decade-scale decrease in b value prior to the M9-class 2011 Tohoku and 2004 Sumatra quakes. Geophys Res Lett 39:L20304. https://doi.org/10.1029/2012GL052997

Obara K, Kato A (2016) Connecting slow earthquakes to huge earthquakes. Science 353:253-257. https://doi.org/10.1126/science.aaf1512pmi d:27418504

Obara K, Kasahara K, Hori S, Okada Y (2005) A densely distributed high-sensitivity seismograph network in Japan: hi-net by National Research Institute for Earth Science and Disaster Prevention. Rev Sci Instrum 76:021301. https://doi.org/10.1063/1.1854197

Okada Y, Kasahara K, Hori S, Obara K, Sekiguchi S, Fujiwara H, Yamamoto A (2004) Recent progress of seismic observation networks in JapanHi-net, F-net, K-net and KiK-net. Earth Planets Space. https://doi. org/10.1186/BF03353076

Ozawa S (2017) Long-term slow-slip events along the Nankai trough subduction zone after the 2011 Tohoku earthquake in Japan. Earth Planets Space 69:56. https://doi.org/10.1186/s40623-017-0640-4

Ozawa S, Murakami M, Tada T (2001) Time-dependent inversion study of the slow thrust event in the Nankai trough subduction zone, southwest Japan. J Geophys Res 106:787-802

Ozawa S, Suito H, Imakiire T, Murakami M (2007) Spatiotemporal evolution of aseismic interplate slip between 1996 and 1998 and between 2002 and 2004, Bungo channel, southwest Japan. J Geophys Res 112:B05409. https ://doi.org/10.1029/2006JB004643

Ozawa S, Yarai H, Imakiire T, Tobita M (2013) Spatial and temporal evolution of the long-term slow-slip in the Bungo Channel, Japan. Earth Planets Space 65:67-73. https://doi.org/10.5047//eps.2012.06.009

Rubinstein JL, La Rocca M, Vidale JE, Creager KC, Wech AG (2008) Tidal modulation of nonvolcanic tremor. Science 319:186-189. https://doi. org/10.1126/science.1150558
Scholz CH (1968) The frequency-magnitude relation of microfracturing in rock and its relation to earthquakes. Bull Seis Soc Amer 58:399-415

Scholz CH (2015) On the stress dependence of the earthquake b value. Geophys Res Lett 42:1399-1402. https://doi.org/10.1002/2014GL062863

Schorlemmer D, Wiemer S (2005) Microseismicity data forecast rupture area. Nature 434:1086. https://doi.org/10.1038/4341086a

Schorlemmer D, Wiemer S. Wyss M (2004) Earthquake statistics at Parkfield: 1 Stationarity of b values. J Geophys Res 109:B12307. https://doi. org/10.1029/2004JB003234

Schorlemmer D, Hirata N, Ishigaki Y, Doi K, Nanjo KZ, Tsuruoka H, Beutin T, Euchner F (2018) Earthquake detection probabilities in Japan. Bull Seismol Soc Am 108(2):702-717. https://doi.org/10.1785/0120170110

Shelly DR, Beroza GC, Ide S, Nakamura S (2006) Low-frequency earthquakes in Shikoku, Japan, and their relationship to episodic tremor and slip. Nature 442:188-191. https://doi.org/10.1038/nature04931

Takagi R, Obara K, Maeda T (2016) Slow slip event within a gap between tremor and locked zones in the Nankai Subduction zone. Geophys Res Lett 43:1066-1074. https://doi.org/10.1002/2015GL066987

Urbancic TI, Trifu Cl, Long JM, Young RP (1992) Space-time correlations of b values with stress release. Pure Appl Geophys 139:449-462

Utsu T (1992) On seismicity, in: Report of Cooperative Research of the Institute of Statistical Mathematics. Inst Stat Math Tokyo 34:139-157

Waldhauser F, Ellsworth WL (2000) A double-difference earthquake location algorithm: method and application to the northern Hayward fault, California. Bull Seismol Soc Am 90:1353-1368. https://doi.org/10.1785/01200 00006

Warren NW, Latham GV (1970) An experimental study of thermally induced microfracturing and its relation to volcanic seismicity. J Geophys Res 75:4455-4464. https://doi.org/10.1029/JB075i023p04455

Watanabe H (1971) Determination of earthquake magnitude at regional distance in Zisin. Bull Seism Soc Japan 32:281-296 (in Japanese with an English Abstracts)

Wessel P, Smith WHF (1995) New version of the generic mapping tools released. Eos Trans AGU 76:329. https://doi.org/10.1029/95EO00198

Wiemer S (2001) A software package to analyze seismicity: ZMAP. Seismol Res Lett 72(3):373-382

Wiemer S, Benoit J (1996) Mapping the b-value anomaly at $100 \mathrm{~km}$ depth in the Alaska and New Zealand subduction zones. Geophys Res Lett 23:1557-1560. https://doi.org/10.1029/96GL01233

Wiemer S, Wyss M (2000) Minimum magnitude of completeness in earthquake catalogs: examples from Alaska, the Western United States, and Japan. Bull Seis Soc Am 90:859-869

Woessner J, Wiemer S (2005) Assessing the quality of earthquake catalogues: estimating the magnitude of completeness and its uncertainty. Bull Seis Soc Am 95(2):684-698. https://doi.org/10.1785/0120040007

Wyss M (1973) Towards a physical understanding of the earthquake frequency distribution. Geophys J R Astr 31:341-359. https://doi.org/10.1111/j.1365246x.1973.tb06506.x

Yano TE, Takeda T, Matsubara M, Shiomi K (2017) Japan unified high-resolution relocated catalog for earthquakes (JUICE): crustal seismicity beneath the Japanese Islands. Tectonophysics 702:19-28. https://doi.org/10.1016/j. tecto.2017.02.017

Yarai H, Ozawa S (2013) Quasi-periodic slow slip events in the afterslip area of the 1996 Hyuga-nada earthquakes, Japan. J Geophys Res 118:2512-2527. https://doi.org/10.1002/jgrb.50161

Yokota Y, Koketsu K (2015) A very long-term transient event preceding the 2011 Tohoku earthquake. Nat Commun 6:5934. https://doi.org/10.1038/ ncomms6934

Yokota Y, Ishikawa T, Watanabe S, Tashiro T, Asada A (2016) Seafloor geodetic constraints on interpolate coupling of the Nankai trough megathrust zone. Nature 534:374-377. https://doi.org/10.1038/nature17632

\section{Publisher's Note}

Springer Nature remains neutral with regard to jurisdictional claims in published maps and institutional affiliations. 